\title{
Paper
}

\section{Optimization of Shrink Fitting Process of Rotor Shaft for Motor Applying High Frequency Induction Heating}

\author{
EIJI TOMA*† Member
}

(Received August 05, 2017, revised October 08, 2017)

\begin{abstract}
This research is collaborative investigation with the general-purpose motor manufacturer. In order to review construction method in production process, we applied the parameter design method of quality engineering and tried to approach the optimization of construction method. Conventionally, press fitting method has been adopted in process of fitting rotor core and shaft which is main component of motor, but quality defects such as core shaft deflection occurred at the time of press fitting. In this research, as a result of optimization design of "shrink fitting method by high frequency induction heating" devised as a new construction method, its construction method was feasible, and it was possible to extract the optimum processing condition.
\end{abstract}

Keywords: Robust design, Parameter design, Shrink fitting, High frequency induction heating

\section{Introduction}

In recent years, there are frequent cases of recall problems due to quality problems of consumer electronics products and automobiles in the market and betrayal of consumer confidence. The way of manufacturing is also the problem solving type in most cases, and the recurrence prevention type development occupies mainstream in actuality. Especially the recall problem of automobiles, such as the complicated structure of the products themselves, the fact that consumers' eyes became more severe, and that it was impossible to break down all the problems in the design process in shortening the development period, it shows the limit of conventional quality control in the market environment. The reason why the recall cannot be prevented in terms of quality control is because the factors of the recall problem are put in the design and development stage. [4] Therefore, it can be said that it is difficult to reduce this problem unless innovating the way of design and thinking into "prevention" concept. In order to prevent problems in advance, to speed up the development of new products and strengthen the constitution of production technology capabilities, it is desired to advance technology development with high versatility and high reproducibility.

For that purpose, it is important for engineers to acquire the idea of quality engineering and how to proceed and fulfill the role and responsibility of engineers. Therefore, "Robust design" is utilized in technology development and product design that account for most of design responsibility. [7] [11]

\footnotetext{
* Corresponding author: toma-e@ tsuruoka-nct.ac.jp

† National Institute of Technology, Tsuruoka College

104 Sawada, Inooka, Tsuruoka, Yamagata 997-8511, Japan
}
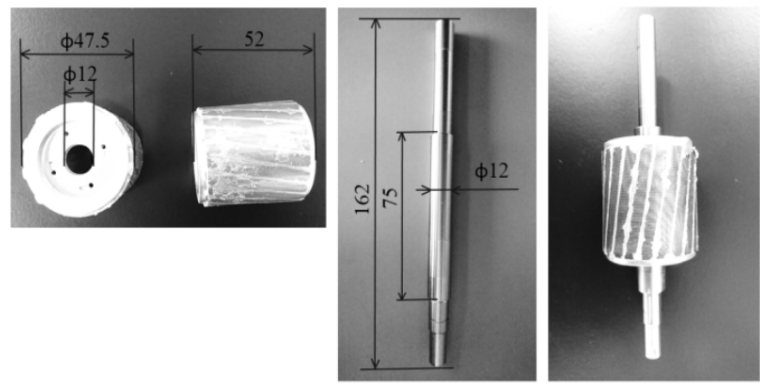

Figure 1: Rotor core and Shaft

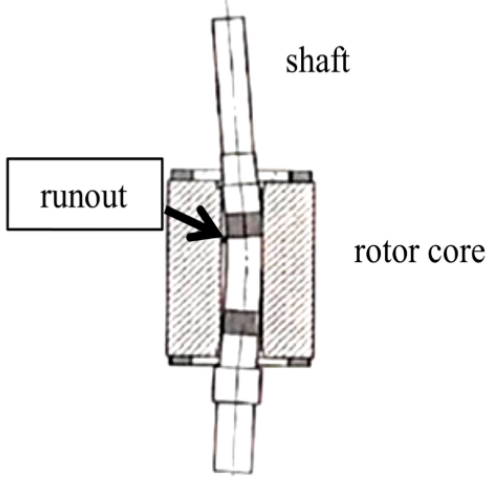

Figure 2: Inferior quality

\section{Research purpose}

This research is a collaborative with a motor manufacturer, and we tried approach to optimization of construction method by applying parameter design of quality engineering for the purpose of reviewing construction method in production process. Fig. 1 shows the rotor core and the shaft, which are the main components of the motor used in 


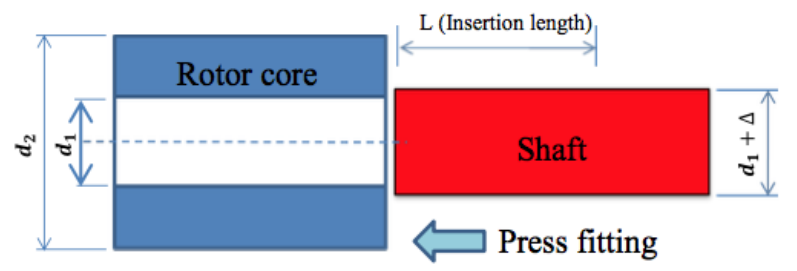

Figure 3: Press fitting model

this study. [1]

In the process of joining the rotor core and the shaft, the press-fitting method has been adopted conventionally, but as shown in Fig. 2, the quality defect of "rotor runout" of the rotor shaft occurring at the time of press-fitting has occurred. Simulation analysis reveals that the factor is caused by an unbalanced load at the time of press-fitting the shaft. [3] [4]

Figure 3 shows the calculation model of the strength of the required interference at the time of press fitting.

【Formula】

- Internal pressure between cylinder and shaft after joining: $p$

$$
p=\frac{d_{2}^{2}-d_{1}^{2}}{2 d_{1} d_{1}^{2}} \cdot E \cdot \Delta
$$

$E$ : Young's modulus $(=201[\mathrm{GPa}]), \Delta$ : interference

- Area of junction: $A$

$$
A=\pi d_{1} L
$$

\section{$L$ : Insertion length}

- Transmission torque: $T$

$$
T=\mu p A d_{1} / 2
$$

$\mu$ : Coefficient of friction $(=0.15)$

\section{【Specificantion】}

- Required rotation transmission torque: $T=70[\mathrm{~N} \cdot \mathrm{m}]$

- Drawing load: $F=5000[\mathrm{~N}]$

- Core inner diameter: $d_{1}=\phi 12$ [mm]

- Core outer diameter: $d_{2}=\phi 47.6[\mathrm{~mm}]$

- Insertion length: $L=40$ [mm]

【Calculation result】

- Area of junction: $A=\pi d_{1} L=1.51 \times 10^{3}\left[\mathrm{~mm}^{2}\right]$ Internal pressure between cylinder and shaft after joining: $p=51.5\left[\mathrm{~N} / \mathrm{mm}^{2}\right]$

- Interference: $\Delta=64.5[\mu \mathrm{m}]$

- Required heating temperature: $\Delta T$ $\Delta=d_{1} \cdot \alpha \cdot \Delta T \rightarrow \Delta T=\Delta /\left(\alpha \cdot d_{1}\right)=444\left[{ }^{\circ} \mathrm{C}\right]$ $\alpha$ :Coefficient of linear expansion $\left(=12.1 \times 10^{-6}\left[/{ }^{\circ} \mathrm{C}\right]\right)$

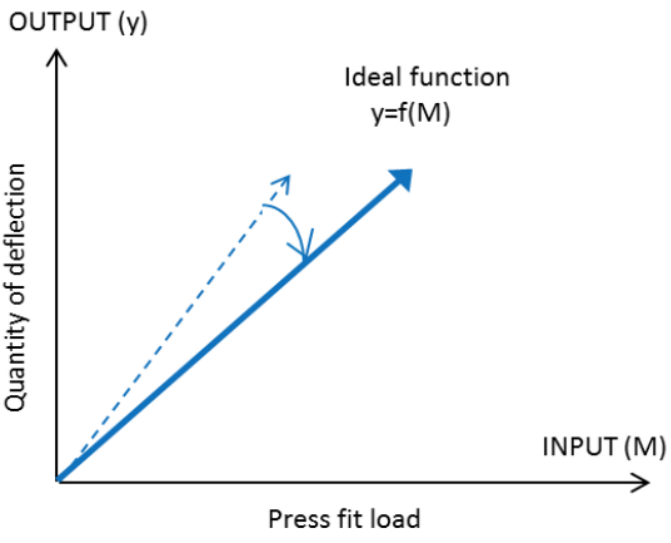

Figure 4: Relation of ideal function

As a result of the previous research, it was possible to optimize the press fitting method by setting the ideal function (Fig. 4) by applying the parameter design, and extract the processing condition to reduce the occurrence of core runout of the rotor shaft. [2] [7]

However, it turned out that it is necessary to change the processing conditions of the press-fitting method if the target rotor shaft diameter changes according to the standard. Although it was able to suppress core runout, in fact, due to the lack of process capability, $100 \%$ non-defective rate could not be achieved, and the current situation is that it has not led to abolishment of all inspections in process.

Therefore, as a new construction method, "shrink fitting method by high frequency induction heating" was devised, and attempts were made to optimize the construction method by applying parameter design which is an effective means for efficiently evaluating the feasibility of the construction method. Shrink fitting is a method of heating the rotor to about the recrystallization temperature and smoothly fitting the shaft by expanding the diameter of the shaft insertion hole. Compared with press-fitting, this method has the advantage that it does not apply a large load to the shaft, it hardly causes a runout at the time of insertion, and even if the shaft diameter changes, it can deal with the same conditions.

In addition, the high-frequency induction heating method has less influence on the work environment, is easier to control, and makes effective use of the space possible than other methods. In particular, from the viewpoint of improving productivity, there is a great merit that rapid heating is possible. [3]

\section{Parameter design}

The concept of robust design in quality engineering is shown in Fig. 5. Robust design is an idea of improving technology to bring it closer to what it should be, and robust means "stability" in quality engineering. [2]

Parameter design is a method of evaluating the functionality and determining the parameter value of the system. Parameters are design constants and components of the system and are selected as control factors in parameter design experiments. Improve robustness by intentionally generating 


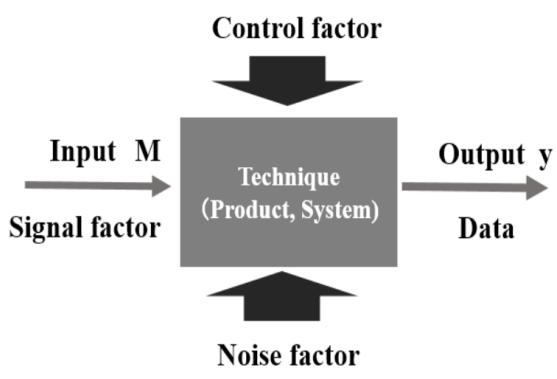

Figure 5: Robust Design

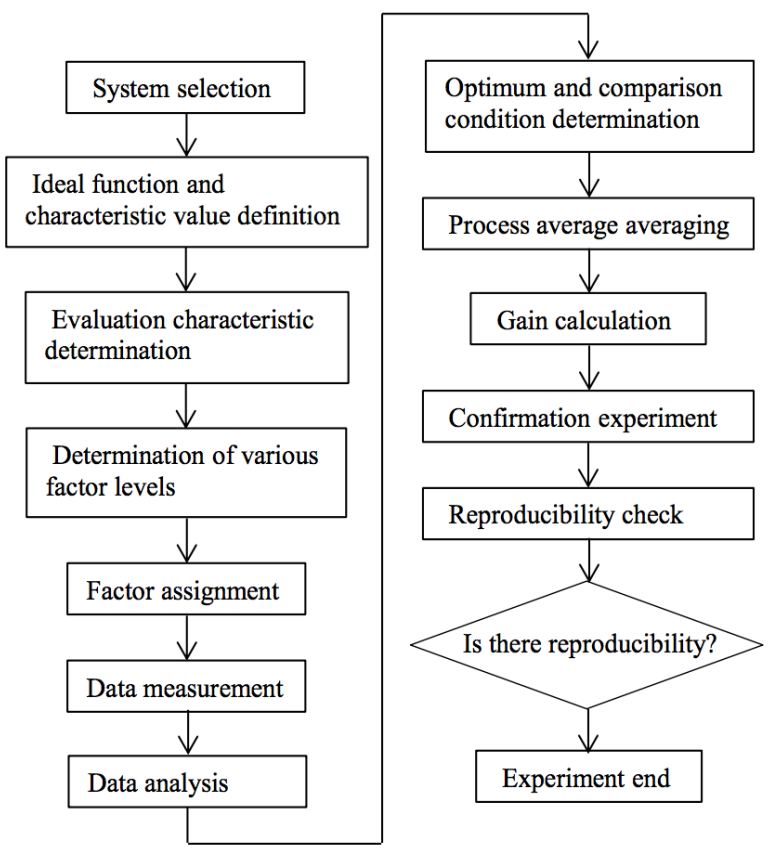

Figure 6: Parameter design procedure

variations with noise factors among combinations of processing conditions and optimizing the level of strong control factors that can counter the variation. [7] [14]

3.1 Procedure of parameter design The procedure of parameter design is shown in Fig. 6. Parameter design begins with clarifying the "function" of the engineering system. Define functions as ideal functions of system input (signal factor) and output (characteristic value). In order to realize the ideal function, experiments are carried out efficiently using the orthogonal table and grasp the magnitude of the effect of each control factor with SN ratio and sensitivity. [12] After that, the process of determining the optimum condition and the comparison condition from the factor effect diagram, predicting the magnitude of improvement by finding the average value of each step, and verifying the reproducibility of the optimum condition gain at the end.

3.2 Clarification of target function In parameter design, how to capture the target function is important. Target function refers to the role that the system should play. The quality characteristics are generally divided as follows.
- smaller-is-better properties (nonnegative and smaller the better)

- larger-is-better properties (nonnegative and larger the better)

- nominal-is-best properties (There is a target value)

- zero nominal-is-best properties (zero is the target value)

By taking up the target function, the design information can be utilized in other similar products, and the versatility of the technology is expanded. [14]

3.3 Determination of signal factor An input signal for changing the output property $\mathrm{y}$ is called a signal factor and is represented by $M$. The signal factor changes the output properties, and selects what can control its value. In general, consider the proportional relation with the ideal relationship of input and output as equation (1). [4]

$$
\gamma=\beta M
$$

3.4 Dynamic characteristics and $\mathrm{S} / \mathrm{N}$ ratio The $\mathrm{SN}$ ratio of the dynamic characteristic is used for functional evaluation. Dynamic characteristics are widely used not only for functionality but also for evaluation of products and processes. Both processes and products should not perform satisfactorily under good conditions, but stable outputs should be obtained even if there are various noises affecting the functional characteristics.

Functionality evaluation means that by examining the linearity of the output by changing the input signal, this is represented by the $\mathrm{SN}$ ratio of the dynamic characteristic. The data processing method and SN ratio calculation based on this relationship are as follows. The $\mathrm{SN}$ ratio of the dynamic characteristics shown here is for the simplest case, and the calculation formula of the $\mathrm{SN}$ ratio changes depending on how the signal is given, how the noise is given, and the like. $[5] \sim[7][13]$

Table 1: SN ratio symbol

\begin{tabular}{|c|c|c|c|c|c|}
\hline $\mathrm{N}$ & $M_{1}$ & $M_{2}$ & $\ldots$ & $M_{k}$ & $L$ \\
\hline$N_{1}$ & $Y_{11}$ & $Y_{12}$ & $\ldots$ & $Y_{1 k}$ & $L_{1}$ \\
\hline $\mathrm{N}_{2}$ & $Y_{21}$ & $Y_{22}$ & $\ldots$ & $Y_{2 k}$ & $L_{2}$ \\
\hline
\end{tabular}

$L_{1}, L_{2}:$ Linear equation

$$
\begin{aligned}
& L_{1}=M_{1} Y_{11}+M_{2} Y_{12}+\cdots+M_{k} Y_{1 k} \\
& L_{2}=M_{1} Y_{21}+M_{2} Y_{22}+\cdots+M_{k} Y_{2 k}
\end{aligned}
$$

$r$ : Effective divider

$$
r=M_{1}^{2}+M_{2}^{2}+\cdots+M_{k}^{2}
$$

$S_{T}:$ Total variation

$$
S_{T}=Y_{1 k}^{2}+Y_{2 k}^{2}+\cdots+Y_{2 k}^{2}
$$


$S_{\beta}$ : Variation of proportional term $\beta$

$$
S_{\beta}=\left(L_{1}+L_{2}\right)^{2} / 2 r
$$

$S_{(N \times \beta)}$ : Variation of noise factor $\mathrm{N}$

$$
S_{N \times \beta}=\left(L_{1}-L_{2}\right)^{2} / 2 r
$$

$V_{e}$ : Noise variance

$$
V_{e}=(2 k-2)^{-1}\left(S_{e}-S_{\beta}-S_{N \times \beta}\right)
$$

$V_{N}$ : Total noise variance

$$
V_{N}=(2 k-1)^{-1}\left(S_{T}-S_{\beta}\right)
$$

$\eta: \mathrm{SN}$ ratio

$$
\eta=10 \log \left\{(2 r)^{-1}\left(S_{\beta}-V_{e}\right) / V_{N}\right\}
$$

S: Sensitivity

$$
S=10 \log (2 r)^{-1}\left(S_{\beta}-V_{e}\right)
$$

3.5 Selection and allocation of factors In the experiment of parameter design, three factors of control factor, signal factor, and noise factor are selected.

The control factor is a factor that satisfies the target function and selects the optimum condition for determining a stable system. In the parameter design, as many factors as possible are considered in the experiment, which seems to be effective in improving the $\mathrm{SN}$ ratio from the parameters. It is usually allocated inside the orthogonal table and is a factor that can be freely selected by the designer.

Signal factor is a factor used for parameter design of dynamic characteristics and changes in conjunction with characteristics to match with target value. It is allocated to the outside of the orthogonal table to which the control factor is allocated (multiple placement).

The noise factor is a factor that causes the system to deviate from the ideal function and cannot be freely selected by the designer. Like the signal factor, it is allocated to the outside (multiple placement). In general, there are cases where internal disturbance (such as factors of variations caused within the system, wear and deterioration of parts, etc.), disturbance (factors of variations added from the outside of the system, environmental and usage conditions, etc.), differences between products (variations between lots etc.) are classified. [7]

3.6 Data analysis Find the $\mathrm{SN}$ ratio $(\eta)$ and sensitivity of the data obtained in the orthogonal table experiment. In order to estimate the factor effect, average value by level is obtained and an auxiliary table is prepared. The optimum condition is decided by choosing a level with a high SN ratio from the response graph showing the auxiliary table as a graph.

Next, estimate the factor effect, and obtain the process average of the optimum condition and the current condition by using the control factor having a large influence on the $\mathrm{SN}$ ratio and the sensitivity, respectively. The gain is estimated from the difference between the process average of the SN ratio of the optimum condition and the current condition. [6]

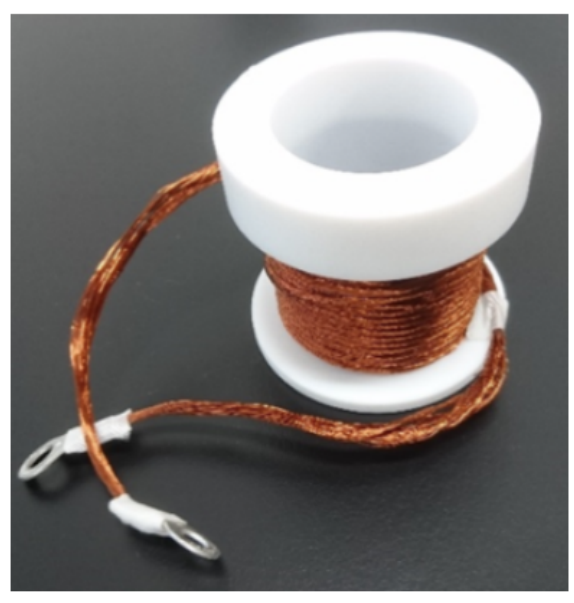

Figure 8: Bobb in and Coil

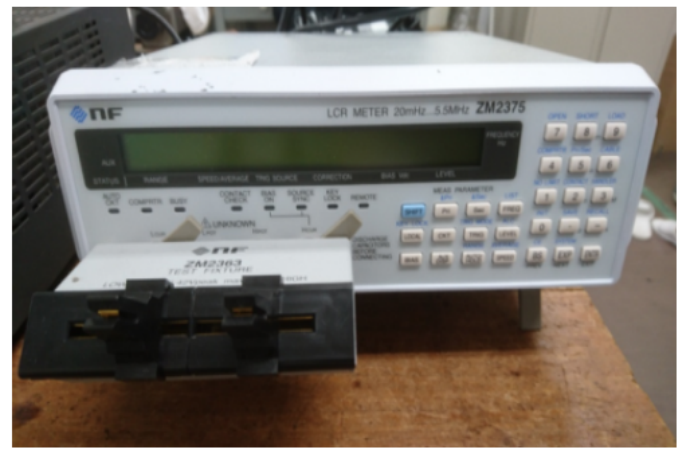

Figure 9: LCR meter

3.7 Confirmation experiment Confirmation experiment is to perform orthogonal table experiment with two conditions of optimum condition and current condition obtained from data analysis. From the experimental results, SN ratio, sensitivity, and gain are obtained and compared with the estimated value.

If the difference from the estimate is large, it means that there is no reproducibility of the orthogonal table experiment. In this case, since it is considered that the interaction between the control factors is large, a technical reexamination is required for the control factor. [11]

\section{Experimental system}

Figure 7 shows the process outline of the experimental system (shrink fit method) in this research. We have devised an automated system by adopting a scalar robot applicable to a practical factory production system.

4.1 Test machine for experiment First, a method of preparing the experimental coil used in this experiment will be described.

The coil was manufactured in a shape wound with insulated winding wound around a bobbin large enough to accommodate the rotor core with high heat resistance (Fig. 8). In this experiment, a Teflon bobbin with high heat resistance was adopted, and a magnet wire with high heat resistance 


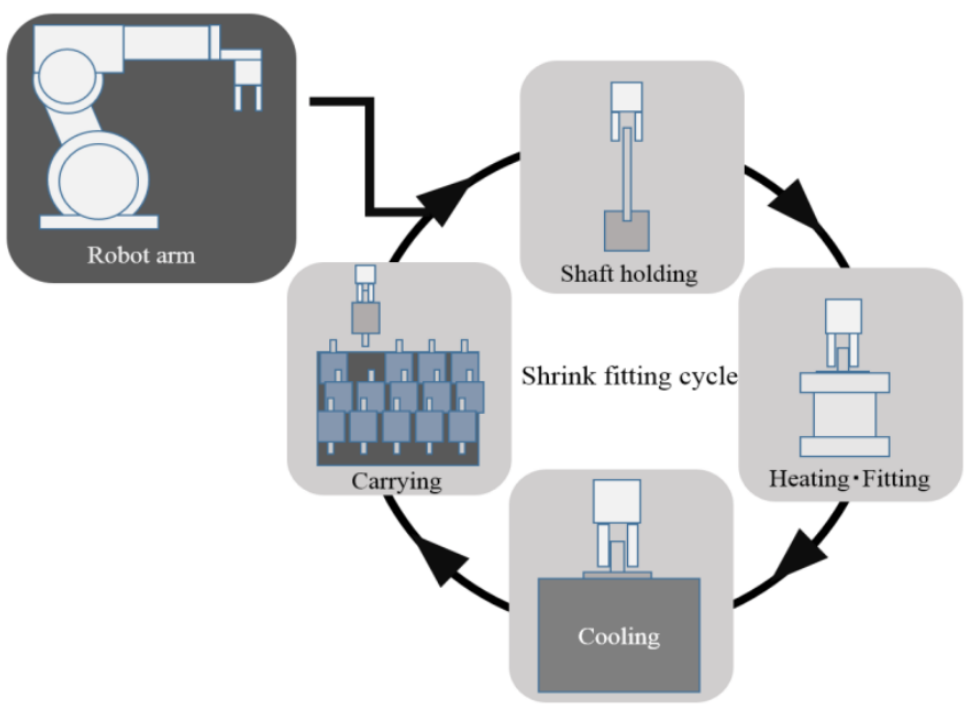

Figure 7: Shrink fitting System

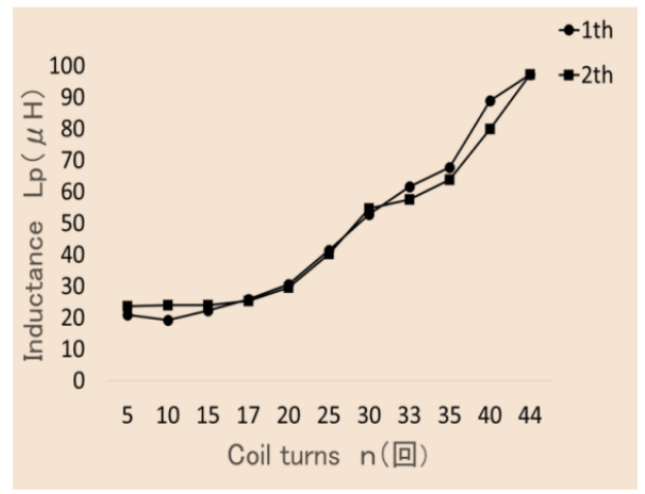

Figure 10: Relation of Coil turns and Inductance

was used for the coil winding. Since it is necessary to set the number of turns of the coil according to the allowable inductance of the high-frequency induction heating device to be used, it was adjusted while measuring the inductance in the LCR meter (Fig. 9). [15]

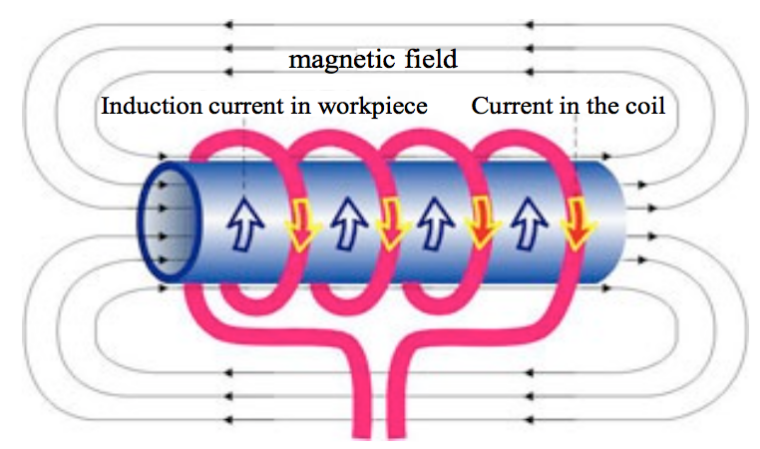

Figure 11: Principle of Induction Heating

The high-frequency induction heater used in this experiment adopts the $\mathrm{IH}$ inverter $(3 \mathrm{~kW})$, and the allowable inductance is $60 \sim 70 \mu \mathrm{H}$. Fig. 10 shows measurement results of inductance.

4.2 Principle of high frequency induction heating Figure 11 shows the principle of high frequency induction

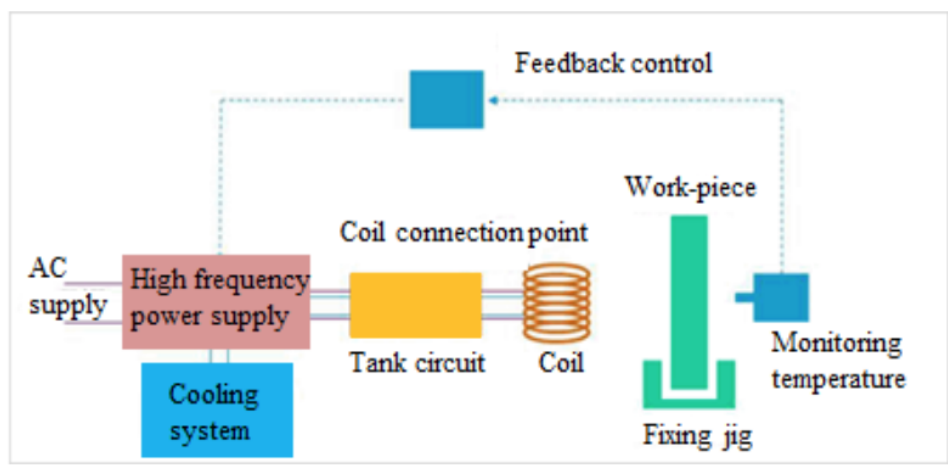

Figure 12: System configuration of high frequency induction heating device 
Table 2: Control factors

\begin{tabular}{l}
\hline Control factor \\
\hline IND Power(\%) $\cdot$ Heating time(s) \\
Coil type \\
Leave time after insertion(min) \\
Cooling system \\
\hline
\end{tabular}

Table 3: Signal factors

\begin{tabular}{cccc}
\hline & M1 & M2 & M3 \\
\hline Signal factor & $\phi 12$ & $\phi 12.5$ & $\phi 15$ \\
\hline
\end{tabular}

Table 4: Noise factors

\begin{tabular}{cccc}
\hline & N1 & N2 & N0 \\
\hline Noise factor & $30 \mu \mathrm{m}$ & $60 \mu \mathrm{m}$ & Average \\
\hline
\end{tabular}

heating. High-frequency induction heating is a method of heating by utilizing electricity and magnetism (conversion of electricity to magnetism). It can also be said to selfheat the metal without contact. Magnetic force is generated when an electric current is passed through the coil, and Joule heat is generated by the eddy current flowing in the conductor and the electric resistance of the metal by magnetic flux change and electromagnetic induction, and the metal rapidly self-heats. By applying this principle, we constructed a high frequency induction heating system as shown in Fig. 12. [15]

\section{Experiment by parameter design}

5.1 Determination of various factors Table 2 4 show various factors of this experiment. As for the control factor, the shrink fitting condition of the rotor shaft is allocated to each level, the signal factor is three types of shaft diameters $\phi 12(\mathrm{~mm}), \phi 12.5(\mathrm{~mm}), \phi 15(\mathrm{~mm})$ with different outer diameters, the error factor is $30 \mu \mathrm{m}$ And $60 \mu \mathrm{m}$. [10]

5.2 Creation of a level table The three levels of IND power and heating time are extracted from the results of preliminary experiments with a high frequency induction heating device (Table 5). The shape of the coil jig was set to three with short winding width, standard one, long one. From this level table, we created an "orthogonal array", a statistical tool for optimization methods, to formulate an experimental plan.

5.3 Assignment to orthogonal array and experiment An orthogonal array is a table defining assignments such that combinations of levels of arbitrary factors appear the same number of times in combinations of experimental levels. The number of experiments is determined by the scale of the orthogonal array and is represented by the experiment number shown at the left end of the orthogonal array. The number of experiments this time is $9 \times 6=54$ times, and the upper row in the horizontal direction represents the type of control factor allocated. The numerical values and letters listed below it represent the level of each control factor. The
Table 5: Table of level

\begin{tabular}{lccc}
\hline Control factor & level1 & level2 & level3 \\
\hline $\begin{array}{l}\text { ND Power(\%) } \\
\text { Heating time(s) }\end{array}$ & $30 \cdot 240$ & $60 \cdot 120$ & $90 \cdot 95$ \\
$\begin{array}{l}\text { Coil type } \\
\begin{array}{l}\text { Leave time after } \\
\text { insertion(min) }\end{array}\end{array}$ & Short & Standard & Long \\
\begin{tabular}{l} 
Cooling system \\
\hline
\end{tabular} & Air & Water & Mist \\
\hline
\end{tabular}

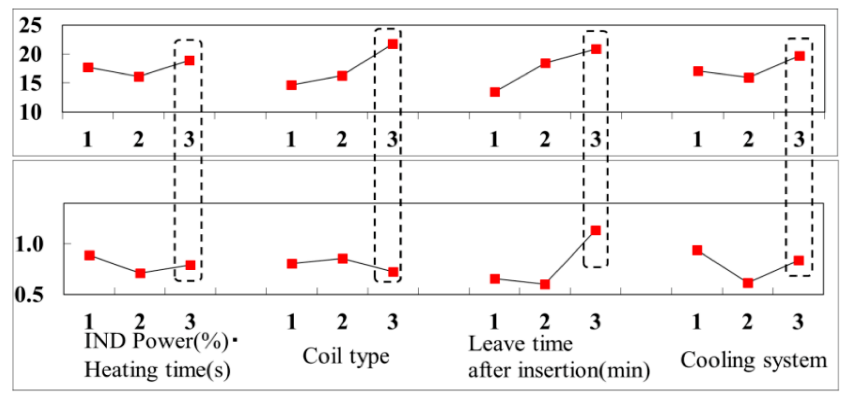

Figure 13: Response graph

advantage of using an orthogonal array is reduction of the number of experiments. In the case where the orthogonal array L9 is not used, the number of times of the experiment is $3^{4} \times 6=486$ times. Table 6 shows the L9 orthogonal array with the level assigned. [10]

5.4 Calculation of experiment result and $\mathrm{SN}$ ratio Table 7 shows the calculation process of SN ratio calculated from experimental data, and Table 8 shows experimental data and $\mathrm{SN}$ ratio values. The $\mathrm{SN}$ ratio is an evaluation index of robustness, which is calculated as a signal-to-noise ratio taking the ratio of useful component and harmful component, and it is preferable that the numerical value is large. The factor effect of a harmful component represents a variation effect from an ideal function with a component whose output unintentionally changes.

In the parameter design, the scale of the evaluation called $\mathrm{SN}$ ratio is obtained, and ultimately the presence or absence of the effect is judged on the response graph to obtain the optimum condition.

5.5 Creating response graph Figure 13 shows the $\mathrm{SN}$ ratio and sensitivity for each control factor expressed in a response graph. The factor effect represents the influence of a factor or a combination of factors on a characteristic value, and the diagram showing this is a response graph. The meaning of this diagram shows that a control factor with a large $\mathrm{S} / \mathrm{N}$ ratio in the vertical direction is effective in suppressing the shaft runout in the shrink fitting. [7] [8]

The levels judged to be optimum in Fig. 13 are the factors "IND Power: 90 (\%) [95 (s)]", "Coil Jig Shape: Length", "leaving time: 1 (min)", and " cooling method: mist".

5.6 Extraction of optimal conditions Table 9 shows the extraction results of combinations of control factor levels considered to be optimum in the experiment from the response graph of the previous section. 
Table 6: Table of level

\begin{tabular}{ccccc}
\hline No. & $\begin{array}{c}\text { ND Power(\%) } \\
\text { Heating time(s) }\end{array}$ & Coil type & $\begin{array}{l}\text { Leave time after } \\
\text { insertion(min) }\end{array}$ & Cooling system \\
\hline 1 & $30 \cdot 240$ & Short & 0 & Air \\
2 & $30 \cdot 240$ & Standard & 0.5 & Water \\
3 & $30 \cdot 240$ & Long & 1 & Mist \\
4 & $60 \cdot 120$ & Short & 0.5 & Mist \\
5 & $60 \cdot 120$ & Standard & 1 & Air \\
6 & $60 \cdot 120$ & Long & 0 & Water \\
7 & $90 \cdot 95$ & Short & 1 & Water \\
8 & $90 \cdot 95$ & Standard & 0 & Mist \\
9 & $90 \cdot 95$ & Long & 0.5 & Air \\
\hline
\end{tabular}

Table 7: Table of level

\begin{tabular}{rrrrrrrrrrr}
\hline No. & $\mathrm{ST}$ & $\mathrm{L} 1$ & $\mathrm{~L} 2$ & $\mathrm{r}$ & $\mathrm{S} \beta$ & $\mathrm{SN} \times \beta$ & $\mathrm{Se}$ & $\mathrm{Vn}$ & $\mathrm{Ve}$ & $\eta(\mathrm{db})$ \\
\hline 1 & 483.0 & 269.0 & 60.5 & 164.8 & 219.6 & 131.9 & 131.5 & 52.7 & 32.9 & 10.24 \\
2 & 209.3 & 70.5 & 114.1 & 92.3 & 184.6 & 10.3 & 14.3 & 4.9 & 3.6 & 15.65 \\
3 & 562.3 & 305.1 & 252.0 & 278.6 & 557.1 & 5.1 & 0.1 & 1.0 & 0.0 & 27.35 \\
4 & 137.0 & 55.0 & 67.5 & 61.3 & 122.5 & 1.3 & 13.2 & 2.9 & 3.3 & 16.14 \\
5 & 656.0 & 358.0 & 246.0 & 302.0 & 604.0 & 20.8 & 31.2 & 10.4 & 7.8 & 17.58 \\
6 & 45.0 & 21.0 & 17.5 & 19.3 & 38.5 & 0.3 & 6.2 & 1.3 & 1.5 & 14.54 \\
7 & 436.0 & 253.0 & 149.0 & 201.0 & 402.0 & 26.9 & 7.1 & 6.8 & 1.8 & 17.70 \\
8 & 362.6 & 101.5 & 217.2 & 159.4 & 318.7 & 42.0 & 1.9 & 8.8 & 0.5 & 15.59 \\
9 & 184.0 & 78.0 & 102.0 & 90.0 & 180.0 & 3.2 & 0.8 & 0.8 & 0.2 & 23.52 \\
\hline
\end{tabular}

However, this is the extraction result obtained from the L9 experimental results, and it is necessary to confirm and evaluate the reliability and reproducibility of the experiment by confirmatory experiment. [9]

5.7 Confirmation of reliability Table 10 shows calculation results of estimated values under optimum conditions, current conditions, and reference conditions. The estimated value of the optimum condition was higher than the other conditions. Based on this result, it was confirmed whether the L9 orthogonal array test result is reliable. [11]
The maximum value and the minimum value of the $\mathrm{SN}$ ratio obtained in the L9 orthogonal array are determined, and from the value of $10 \%$ of the difference, if the difference from the estimated $\mathrm{SN}$ ratio is within the range of $10 \%$, if it is reliable.

Table 11 shows the evaluation results of reliability. In the evaluation method in this experiment, it was judged that reliability is given to orthogonal table experiment by adopting evaluation of characteristic value (nominal-is-best properties) against a certain target value.

Table 10: Estimated value

\begin{tabular}{lcccccc}
\hline & & $\begin{array}{c}\text { IND Power(\%) } \\
\text { Heating time(s) }\end{array}$ & Coil type & $\begin{array}{l}\text { Leave time after } \\
\text { insertion(min) }\end{array}$ & Cooling system & Estimated value \\
\hline $\begin{array}{l}\text { Optimum } \\
\text { condition }\end{array}$ & level & 3 & 3 & 3 & 3 & 28.54 \\
Current & level & 18.94 & 21.80 & 20.88 & 19.69 & \\
condition & SNR & 16.09 & 16.28 & 18.44 & 15.96 & 13.99 \\
$\begin{array}{l}\text { Reference } \\
\text { condition }\end{array}$ & level & 2 & 3 & 1 & 2 & 14.54 \\
\hline
\end{tabular}

Table 11: Reliability confirmation

\begin{tabular}{cccc}
\hline \multicolumn{2}{c}{ L9 experiment SNR } & \multicolumn{2}{c}{ Reliability confirmation by reverse estimation } \\
\hline Maximum & 27.35 & Average of current condition & 13.99 \\
Maximum & 10.24 & Reverse estimated value of Response graph & 28.54 \\
Difference & 17.11 & & - \\
$10 \%$ of difference & 1.711 & $>$ & -14.55 \\
\hline \multicolumn{2}{c}{ Judgment } & Reliable \\
\hline
\end{tabular}


Table 8: Experimental result

\begin{tabular}{|c|c|c|c|c|c|}
\hline \multirow{3}{*}{ No. } & \multirow{3}{*}{$\begin{array}{l}\text { Noise } \\
\text { Symbol }\end{array}$} & \multicolumn{3}{|c|}{$\operatorname{Deflection}(\mu \mathrm{m})$} & \multirow{3}{*}{$\mathrm{SN}$ ratio $(\mathrm{db})$} \\
\hline & & M1 & M2 & M3 & \\
\hline & & 12 & 12.5 & 15 & \\
\hline \multirow{3}{*}{1} & N1 & 16 & 5 & 13 & \multirow{3}{*}{10.24} \\
\hline & N2 & 1 & 4 & 4 & \\
\hline & No & 8.5 & 4.5 & 8.5 & \\
\hline \multirow{3}{*}{2} & N1 & 6 & 4 & 3 & \multirow{3}{*}{15.65} \\
\hline & $\mathrm{N} 2$ & 12 & 0.5 & 2 & \\
\hline & NO & 9 & 2.25 & 2.5 & \\
\hline \multirow{3}{*}{3} & N1 & 12 & 10 & 9.5 & \multirow{3}{*}{27.35} \\
\hline & $\mathrm{N} 2$ & 10 & 8 & 8 & \\
\hline & NO & 11 & 9 & 8.75 & \\
\hline \multirow{3}{*}{4} & N1 & 4 & 6 & 2 & \multirow{3}{*}{16.14} \\
\hline & $\mathrm{N} 2$ & 4 & 4 & 7 & \\
\hline & N0 & 4 & 5 & 4.5 & \\
\hline \multirow{3}{*}{5} & N1 & 10 & 14 & 12 & \multirow{3}{*}{17.58} \\
\hline & $\mathrm{N} 2$ & 10 & 4 & 10 & \\
\hline & No & 10 & 9 & 11 & \\
\hline \multirow{3}{*}{6} & N1 & 3 & 1 & 4 & \multirow{3}{*}{14.54} \\
\hline & $\mathrm{N} 2$ & 3 & 3 & 1 & \\
\hline & No & 3 & 2 & 2.5 & \\
\hline \multirow{3}{*}{7} & N1 & 4 & 15 & 9 & \multirow{3}{*}{17.70} \\
\hline & N2 & 4 & 7 & 7 & \\
\hline & No & 4 & 11 & 8 & \\
\hline \multirow{3}{*}{8} & N1 & 7.5 & 0.6 & 3 & \multirow{3}{*}{15.59} \\
\hline & $\mathrm{N} 2$ & 16 & 4 & 5 & \\
\hline & No & 11.75 & 2.3 & 4 & \\
\hline \multirow{3}{*}{9} & N1 & 4 & 4 & 6 & \multirow{3}{*}{23.52} \\
\hline & N2 & 4 & 6 & 8 & \\
\hline & No & 4 & 5 & 7 & \\
\hline
\end{tabular}

Table 9: Optimum condition

\begin{tabular}{lccc}
\hline $\begin{array}{l}\text { IND } \\
\text { Power(\%) }\end{array}$ & Coil type & $\begin{array}{l}\text { Leave time } \\
\text { after inser- } \\
\text { tion } \\
\text { Heating } \\
\text { time(s) }\end{array}$ & $\begin{array}{l}\text { Cooling } \\
\text { system }\end{array}$ \\
\hline 90.95 & Long & 1 & Mist \\
\hline
\end{tabular}

5.8 Confirmation of reproducibility In the confirmation experiment, the estimated value of the $\mathrm{SN}$ ratio of the selected optimum condition and the current condition was obtained, and experiments were conducted again on the same two types as the orthogonal array experiment to acquire the $\mathrm{SN}$ ratio, and the difference between the estimated values of both and confirmation experiment Comparing the difference (gain), investigate whether the experiment is reproducible or not.

The purpose of the confirmatory experiment is to confirm whether or not to reproduce even when the time, place, environment, etc. change, compared with the orthogonal array
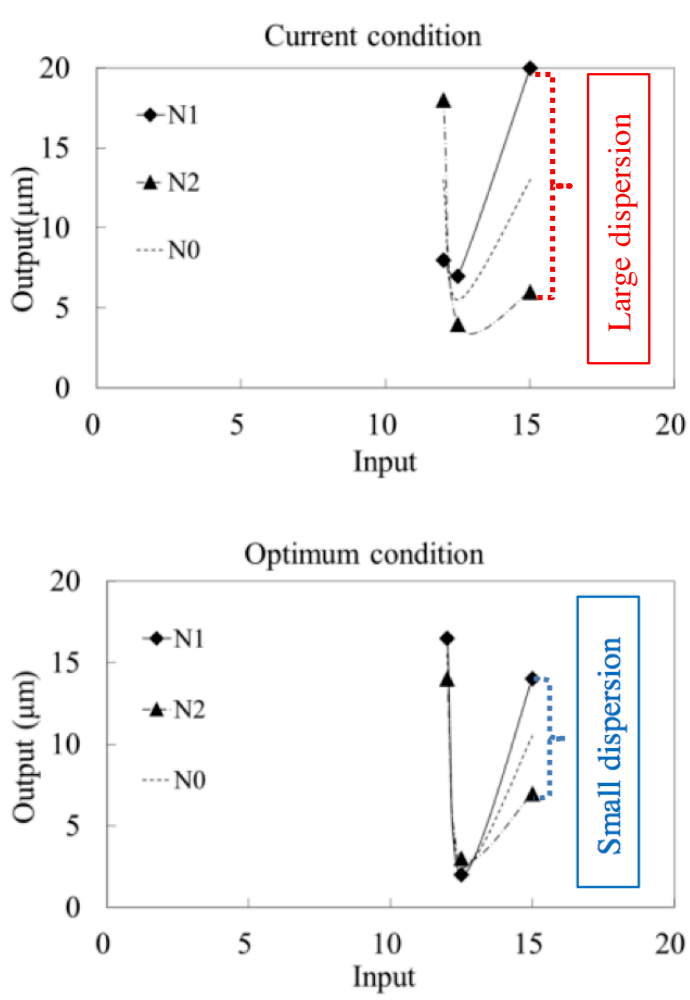

Figure 14: Functionality evaluation graph

experiment. If there is no repeatability, it can be said that it is a poor technology which is highly likely to cause some troubles in the future. [5]

The evaluation results of the confirmation experiment are shown in Table 12. From the result that the reproducibility of the gain is about $50 \%$, it is judged that there is no reproducibility. Specifically, it means the probability that 5 items are reproduced as non-defective products out of 10 good products. [7] [10]

However, in this experiment, it is the greatest purpose to determine whether the shrink fitting method is established or not. Fig. 14 is a graph comparing the optimum condition in functional evaluation and the degree of variation in current condition. It shows the change in the output (core deflection) with respect to the input (shaft diameter) of the noise factor(N1, N2, N0), indicating that the dispersion of the optimum condition is smaller than the current condition.

From this result, it became clear that the shrink fitting method is a robust construction method capable of coping with the change of the shaft diameter.

\section{Conclusion}

In this research, attention was paid to the shrinkage fitting method by high frequency induction heating, and an approach was tried on the feasibility of the shrinkage fitting method applying parameter design which is a representative method of quality engineering. As a result of the research, the SN ratio was obtained from the result of the orthogonal array experiment, and it was possible to extract the combination of the optimum processing condition level from the response graph. 
Table 12: Reproducibility

\begin{tabular}{|c|c|c|c|c|c|c|c|}
\hline \multirow[t]{2}{*}{ Conditions } & \multirow{2}{*}{$\frac{\text { Noise symbol }}{\text { N1 }}$} & \multicolumn{3}{|c|}{$\operatorname{Deflection}(\mu \mathrm{m})$} & \multirow[t]{2}{*}{ Estimated value } & \multirow[t]{2}{*}{ Confirmation value } & \multirow[t]{2}{*}{ Reproducibility } \\
\hline & & 16.5 & 2 & 14 & & & \\
\hline \multirow[t]{3}{*}{ Optimum condition } & N2 & 14 & 3 & 7 & 28.54 & 20.91 & $73 \%$ \\
\hline & No & 15.5 & 2.5 & 10.5 & & & \\
\hline & N1 & 8 & 7 & 20 & & & \\
\hline \multirow{3}{*}{ Current condition } & $\mathrm{N} 2$ & 18 & 4 & 6 & 13.99 & 13.61 & $97 \%$ \\
\hline & No & 13 & 5.5 & 13 & & & \\
\hline & N1 & 14 & 1 & 2 & & & \\
\hline \multirow[t]{3}{*}{ Reference condition } & $\mathrm{N} 2$ & 11 & 9 & 6 & 25.69 & 15.79 & $61 \%$ \\
\hline & No & 13 & 5 & 4 & & & \\
\hline & Gain & & & & 14.55 & 7.31 & $50 \%$ \\
\hline
\end{tabular}

Finally, the shrink fitting method can be practically applied by the confirmation experiment, it is superior to the current construction method, and it is clear that the quality assurance can be technically guaranteed. In the future, we plan to develop process optimization for mass production.

\section{References}

[1] H. Yano : "Technology development of the information design with the computer-Simulation and MT system ”, Japan Standards Association , pp.1-28, 2004

[2] H. Yano : "Introduction to Quality Engineering numeration", Japan Standards Association, pp.128-145, 2002

[3] T. Mori: "Application and Mathematics of the Taguchi Methods", Optimization engineering using the Taguchi Methods, trendy book, pp.39-85, 2005

[4] G. Taguchi : Quality Engineering lecture no.5 "Quality Engineering Casebook - Japan public”, Japan Standards Association, pp.223-240, 1992

[5] H. Yano: "Quality engineering guide to raise an engineer power", Japan Standards Association, pp.79-122, 2011

[6] H. Tsuruta : "Energy ratio type SN ratio", Federation of Japanese technology, pp.13-49, 2016

[7] S. Koshimizu, and M. Suzuki : "Practice Quality Engineering to acquire by experience by a Virtual Experiment", Daily industry newspaper publisher, pp.17-30,35-56, 2007

[8] Y. Watanabe : "Practice Taguchi Methods", Federation of Japanese technology, pp.1-71, 2006

[9] K. Inoue and K. Nakano : "Guide Parameter Design", Federation of Japanese technology, pp.9-30, 2008

[10] M. Ono : "Quality Engineering to learn from the basics", Japan Standards Association, pp.49-118, 2013

[11] M. Hasebe : "Basic Taguchi Methods”,Japan Management Center Association, pp.75-99, 2009

[12] H. Tsuruta: "Key points of function, noise, SN ratio, ULTRA PRACTICE of QUALITY ENGINEERING",Japan Standards Association, pp.34-43,67-106,160-191,2017
[13] H. Tsuruta : "Quality engineering at design and development site Energy ratio type SN ratio", Federation of Japanese technology, pp.17-53,73-114, 2016

[14] M. Hasebe : "Concept of quality engineering", Japan Standards Association, pp.89-112, 2013

[15] H. Uemura : "Recent induction furnace technology", Industrial Heating, Vol.44, No.6, pp.9-17, 2007

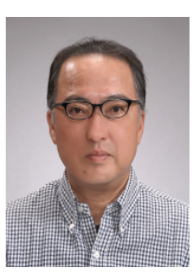

Eiji Toma (Member) He was born in Hokkaido, Japan, on December 17, 1959. When he was engaged as a manufacturing engineer at an automobile parts manufacturer, he acquired a "Professional Engineer (P.E.jp)" and "APEC engineer" in 2010, and is presently an professor at National Institute of Technology, Tsuruoka College. He has worked on research of the quality engineering. He is member of IIAE. 